\title{
CONTEÚDOS ABERTOS E COMPARTILHADOS: NOVAS PERSPECTIVAS PARA A EDUCAÇÃO
}

\author{
Osmar Mantovani \\ Maria Helena Pereira Dias ${ }^{* *}$ \\ HANS LIESENBERG ${ }^{* * *}$
}

\begin{abstract}
RESUMO: Mudanças em curso no cenário de produção e divulgação de conhecimentos bem como algumas questões importantes indutoras de tais mudanças são apontadas. A principal é o desbalanceamento, cada vez maior, entre os interesses da indústria cultural e os da sociedade, em favor da primeira, provocado, em anos recentes, por mudanças sucessivas no direito de propriedade intelectual por pressão da mesma indústria cultural que tem, hoje, o seu modelo de negócio ameaçado por práticas apoiadas por novas tecnologias de informação e comunicação e, especificamente, pela Internet. Tal desbalanceamento cerceia, em particular, a escola na escolha dos recursos mais apropriados para a educação de seus alunos. Um contramovimento promove "conteúdos abertos". Um ambiente que foi desenhado para apoiar a comunidade escolar na publicação e no compartilhamento de conteúdos para, dessa forma, ajudá-la a promover uma educação com parâmetros mais democráticos e adequados às transformações em curso é apresentado.
\end{abstract}

Palavras-chave: Conteúdos digitais. Educação. Autoria. Direitos autorais. Indústria cultural. Internet.

OPEN AND SHARED CONTENTS: NEW PERSPECTIVES FOR EDUCATION

ABSTRACT: Ongoing changes in the scenario of knowledge production and dissemination as well as some of the important issues that induced them are pointed out. The main one is an increasing

* Mestre pelo Instituto de Computação da Universidade Estadual de Campinas (UniCAmp). E-mail: osmar.mantovani@ic.unicamp.br

** Doutora e pesquisadora autônoma.E-mail:mhpdias@gmail.com

*** Doutor pelo Instituto de Computação da Universidade Estadual de Campinas (UNICAMP). E-mail: hans@ic.unicamp.br

Educ. Soc., Campinas, vol. 27, n. 94, p. 257-276, jan./abr. 2006

Disponível em <http://www.cedes.unicamp.br> 
Conteúdos abertos e compartilhados: novas perspectivas para a educação

shift of balance from the interests of society to those of the culture industry promoted, these last years, by successive amendments to the intellectual property rights. These were passed under the pressures of that industry whose business model is nowadays threatened by the practices supported by the new information and communication technologies and the Internet in particular. Such shift of balance specifically limits schools in their choices of the most appropriate resources to educate their students. A counter-movement is promoting "open contents" through an environment, presented here, designed to support the school community in publishing and sharing tasks. It is aimed at helping that community promote an education with more democratic and better-suited parameters for the transformations under way.

Key words: Digital contents. Education. Authorship. Copyright. Cultural industry. Internet.

\section{Reflexões introdutórias}

E ntre as inúmeras formas de diálogo hoje possíveis, e cada vez mais necessárias, entre as tecnologias de comunicação e informação e o campo educacional, especialmente aquele ligado à educação básica, uma delas diz respeito à importância de se compartilhar o conhecimento produzido não só no sentido da divulgação, mas sobretudo no sentido da transformação das informações para a efetivação do conhecimento do outro, seja ele aluno ou professor. É justamente sobre caminhos que se abrem para novas maneiras e possibilidades de compartilhar que o presente texto vai se deter, propondo-se a apresentar dados para o debate que ora se impõe e é travado em diferentes espaços, sejam eles apoiados em suportes de alta tecnologia ou relacionados a esta última, mas tradicionalmente apoiados em material impresso. Tal debate passa necessariamente pela questão dos direitos autorais. Também é apresentado um artefato tecnológico de suporte à produção, partilha e colaboração entre autores, por intermédio da disponibilização de conteúdos ${ }^{1}$ pedagógicos na Internet, como um possível meio para a realização das idéias em debate.

Em anos recentes, as condições impostas pela legislação relacionada aos direitos autorais têm sido cada vez mais restritivas (Lemos, 2005). ${ }^{2} \mathrm{O}$ uso justo de conteúdos, habitualmente autorizado para fomentar a inovação e o avanço da fronteira do conhecimento, está cada 
vez mais cerceado para melhor proteger a indústria cultural, ${ }^{3}$ cujos modelos tradicionais de negócio se encontram ameaçados por novas práticas viabilizadas por tecnologias de informação e comunicação e, em particular, pela Internet.

Uma reação a tal tendência é um novo movimento que promove "conteúdos abertos", isto é, conteúdos publicados sob licenças de uso mais flexíveis. ${ }^{4}$ Tal movimento terá um impacto muito grande sobre o contexto escolar. Os professores e as escolas terão, cada vez mais, facilidades nas escolhas e nos usos de conteúdos avaliados como os mais adequados para a aprendizagem de seus alunos, quanto maior for o número deles liberado sob licenças de uso mais maleáveis.

Conteúdos os mais variados e de real interesse educacional são produzidos em grande número, a toda hora, mas não são divulgados por terem um potencial mercadológico pequeno ou não muito claro. Tais conteúdos acabam se perdendo ao longo do tempo por falta de mecanismos de publicação acessíveis a todos os interessados.

O trabalho aqui apresentado, e já em fase operacional, provê um sistema de publicação de conteúdos de interesse educacional em um diretório eletrônico sob licenças mais liberais escolhidas pelos próprios autores de tais conteúdos. Apenas alguns direitos são preservados, justamente aqueles considerados de fato relevantes para cada autor, e não todos, como é comum no direito autoral vigente, cada vez mais restritivo. Segundo Lemos (2005),

um dos principais problemas do direito autoral 'clássico' é que ele funciona como um grande 'Não'. É comum encontrar, em obras autorais exploradas economicamente, a inscrição 'Todos os direitos reservados' (ou 'All

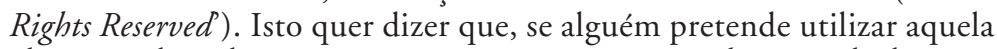
obra, tem de pedir autorização prévia a seu autor ou detentor de direitos. Grosso modo, se alguém faz rabiscos em um guardanapo, aqueles rabiscos já nascem protegidos pelo direito autoral, e qualquer pessoa que deseje utilizá-los precisa pedir permissão ao autor. (...) Entretanto, existe um grande número de autores, detentores de direitos e criadores de modo geral que simplesmente não se importa que outras pessoas tenham acesso às suas obras. (...) Para estas pessoas, não faz sentido econômico, nem artístico, que seus trabalhos se submetam ao regime 'todos os direitos reservados'.

Com relação a licenças de uso mais flexíveis, Lemos (2005) observa que "esta mudança de paradigma quanto ao direito autoral não 
renega o direito autoral tradicional. Ao contrário: fundamenta-se nele e nas prerrogativas legais dos autores de autorizarem a utilização de suas obras como bem entenderem. Trata-se de um deslocamento do eixo 'todos os direitos reservados' para 'alguns direitos reservados' ('all rights reserved para 'some rights reserved')".

O objetivo de licenças de uso mais flexíveis é permitir uma prática mais democrática e criativa, que faculte e não iniba a inovação na produção de bens culturais. Além da publicação no diretório eletrônico, associaçōes anotadas entre conteúdos podem ser explicitadas. Tais associações dão suporte a uma exploração mais dirigida e quebram a segmentação hierárquica do diretório eletrônico. Conteúdos vistos tradicionalmente, por mera convenção, como pertencentes a determinadas disciplinas podem, agora, ter os seus relacionamentos claramente evidenciados e podem, dessa forma, estar mais bem contextualizados.

Fazendo um rápido retrospecto histórico sobre a questão da autoria, é possível lembrar que desde a invenção da imprensa, pelo fato de que imprimir era uma tarefa complexa, demandando processos industriais e envolvendo aspectos econômicos determinados pelo mercado editorial, autores passaram a ser "autoridades", respaldados pelas palavras e histórias que compunham e, também, alçaram a categoria de proprietários dos textos a eles atribuídos, aos quais nada se podia acrescentar, suprimir ou alterar, devendo ser lidos conforme a ordem proposta em páginas, capítulos ou partes. Esta situação criou entre autores e leitores um distanciamento significativo, assumido pelos últimos como quase intransponível.

Questôes mercadológicas, como já afirmamos, cercearam a veiculação de idéias consideradas não-interessantes em termos políticos e, principalmente, econômicos pelas grandes empresas editoriais, silenciando possíveis autores e produtores de conhecimento e, no que concerne aos professores, encerrando entre as paredes da sala de aula bons projetos e conteúdos pedagógicos clamando por divulgação.

É bem verdade que, em épocas anteriores ao advento da imprensa, copistas e comentaristas dos textos sagrados freqüentemente introduziam alteraçôes nos textos que copiavam ou comentavam, mantendo com os manuscritos e com os escritores sagrados uma maior proximidade, muitas vezes tornando-se difícil a identificação do manuscrito original (Fontes, 1991). Essa mesma proximidade entre autores e lei- 
tores foi retomada na segunda metade do século XX, quando diferentes estudiosos do texto como Kristeva (Barthes et al., 1968), Barthes (1987) e Genette (1981), entre outros, verificaram nele a reescrita e o diálogo com um sem-número de outros textos e colocaram em pauta a intertextualidade que, num esforço comparativo - até metafórico -, o hipertexto, patrocinado pelo computador, pode concretizar, conforme proposto por Landow (1995).

O termo "hipertexto" foi usado pela primeira vez por Theodor H. Nelson nos anos de 1960 e refere-se a esse tipo de texto eletrônico, uma tecnologia informática que é, ao mesmo tempo, uma forma de "edição". Segundo o próprio Nelson a expressão refere-se a uma "escritura não-seqüencial, a um texto que bifurca, que permite ao leitor escolher e que se lê melhor em uma tela interativa. De acordo com a noção popular, trata-se de uma série de blocos de textos conectados entre si por nexos, que formam diferentes trajetos para o usuário" (Landow, 1995 , p. 15 , nota 5$)$.

Um hipertexto pode ser entendido como um conjunto de fragmentos de informação (nós) e um conjunto de nexos eletrônicos que os conectam entre si. O termo "hiperdocumento" simplesmente estende a noção hipertextual ao incluir informações visuais, sonoras e animaçóes. O hipertexto, ao possibilitar a passagem do discurso verbal a imagens, mapas, diagramas e sons ou outro fragmento textual, expande a noção de texto muito além do meramente verbal, caminhando ao encontro das formulações pós-estruturalistas no que diz respeito à ênfase na idéia de "texto" (Pereira-Dias, 2000).

A escrita hipertextual como que libera o texto da tirania do autor pela facilidade que oferece a cada leitor de adicionar, alterar ou simplesmente editar um outro texto. Nessa facilidade é que o tema aqui colocado em pauta se baseia, procurando abrir espaço para que novos conhecimentos, gerados por autores até hoje impedidos de vê-los divulgados, sejam compartilhados, enriquecidos, comentados.

\section{Direitos de uso mais flexíveis}

Assim como textos dialogam com outros textos, conhecimentos constroem-se sobre conhecimentos prévios em um movimento reticular em que valores são agregados a valores construídos por outros. Esse mo- 
vimento, contudo, fragiliza-se e quebra-se quando leis de direito autoral passam da proteção justa do esforço criativo do autor para a preservação de um modelo de negócio.

Foucault (1992), em seu conhecido texto "O que é um autor", constata que historicamente os textos, que hoje definiríamos como literatura, passaram a ter autores na medida em que se tornaram transgressores e passíveis de punição, pois, na Antiguidade, narrativas, contos, tragédias, comédias e epopéias circulavam livremente sem que houvesse uma preocupação com a sua autoria. Os textos científicos, ao contrário, deveriam ser avalizados por um autor, como os tratados de medicina, por exemplo.

O primeiro estatuto de direito autoral, entretanto, foi criado na Inglaterra, em 1710, para regular o mercado editorial e atribuir a autoria a textos anteriormente circulantes de forma anônima, e previa a proteção ao autor de uma obra impressa por um período de apenas 14 anos. Assim é que o gesto carregado de riscos da autoria, na qualidade de transgressão conforme Foucault, passou a se constituir um bem, preso ao sistema de propriedade. Desde então, períodos de proteção vêm sendo ampliados. Inicialmente de forma esporádica e recentemente com freqüência cada vez maior. Lessig (2004) aponta a indústria cultural como a força por trás de tais mudanças que visam a conquistar, pouco a pouco, uma perpetuação dos direitos de propriedade sobre as obras de que é detentora.

Ele ilustra isso com o império construído por Walt Disney. Em 1928, Walt Disney criou o Mickey Mouse a partir de um personagem do filme mudo "Steamboat Bill", 5 do cineasta Buster Keaton. Outros personagens e histórias foram derivados dos contos coletados pelos irmãos Grimm, estas já há muito tempo em domínio público e, portanto, um bem cultural comum. A inovação de Walt Disney, portanto, teve como base tais bens culturais, o segundo já não mais protegido por direito autoral. Agora, contudo, sempre que os direitos autorais sobre o Mickey Mouse estão prestes a cessar e ele passar para o domínio público, a legislação é alterada e, além de dar uma sobrevida à proteção autoral do Mickey Mouse, a alteração, por conseqüência, também protege todas as demais obras controladas pela Disney Corporation.

A abrangência inicial do direito autoral regulava apenas a impressão da obra e não impedia a criação de obras derivadas nem regulava outros usos corriqueiros. Em 1831, o período de proteção passou para 42 
anos, em 1909 o direito autoral passou para 56 anos e, a partir de 1962, a lei de direito autoral dos Estados Unidos foi emendada mais de dez vezes para aumentar não só o período de proteção de novas obras, mas também das obras já existentes, isto é, as mudanças sempre retroagiam. O período foi ampliado para 70 anos após a morte do autor. As leis americanas de direito autoral acabam afetando a todos, pois elas são, pouco a pouco, habilmente estendidas para leis internacionais pelos Estados Unidos, preocupados em proteger a sua própria indústria cultural.

Hoje existe um grande sistema constituído por advogados para regular a criatividade, dadas as proporçôes cada vez maiores da abrangência dos direitos autorais, que englobam, inclusive, tecnologias de acesso a conteúdos bem como de controle de sua propriedade intelectual. As proteçốes cada vez mais amplas dão-se à custa da sociedade como um todo. A cultura é cada vez mais controlada e menos livre. Conseqüentemente, a criatividade bem como a inovação são cada vez mais tolhidas já que é cada vez mais difícil construir trabalhos novos a partir dos produzidos no passado. Publicar uma mera página na Internet está se tornando uma atividade de risco, do ponto de vista legal, para os menos avisados, conforme apontado por Kienle (2004).

As mudanças de cenário mais e mais preocupantes induziram diversas ações e iniciativas que pretendem resistir aos controles cada vez maiores sobre a criatividade. Ao passo que a indústria cultural, para manter a pressão sobre os legisladores, tenta reduzir o debate a uma mera questão de propriedade versus pirataria, outras possibilidades entre os domínios privado e público podem ser exploradas, atendendo melhor os interesses da sociedade como um todo do que as leis de direitos de propriedade intelectual.

Destaca-se uma iniciativa em particular, ligada a uma organização não-governamental denominada Creative Commons ${ }^{6}$ (Bens Criativos Compartilhados por Todos), criada oficialmente em 2001 (Hietanen, 2003). Seu objetivo é promover o desenvolvimento de conteúdos ditos abertos. Um conteúdo é aberto, segundo Cedergren (2003), se for "um conteúdo que outros possam melhorar e redistribuir e/ou um conteúdo que é produzido sem nenhuma expectativa de compensação financeira imediata".

A iniciativa da Creative Commons baseia as suas estratégias nas estratégias do movimento de software livre, que se utiliza justamente 
das leis de direito autoral para flexibilizá-las. Como tais leis dão ao autor a prerrogativa de estabelecer as condições de uso de suas obras de acordo com o seu próprio arbítrio, ele pode relaxar as condiçóes determinadas por lei que julgar inadequadas ao estabelecer uma licença específica de uso mais flexível.

No caso do software livre ou de código aberto, condições especiais são estabelecidas em licenças de uso que garantem explicitamente uma série de liberdades e, em geral, introduzem cláusulas que previnem a apropriação indevida por terceiros bem como exigem o reconhecimento da autoria. Ao invés da nota "todos os direitos reservados", comum em declaraçōes de direito autoral, a tônica é "alguns direitos reservados".

Ao passo que as leis de direito autoral garantem ao autor direitos exclusivos, eventualmente transferidos para terceiros, de produção, derivação, distribuição, encenação e exposição, as licenças promovidas pela Creative Commons são "calibráveis" pelos autores que queiram reter alguns direitos ao mesmo tempo em que incentivam o compartilhamento de suas obras com o público em geral segundo termos mais generosos do que os ditados pelas leis de direito autoral.

A Creative Commons promove um leque de licenças de uso mais flexíveis compostas por combinações de cláusulas escolhidas pelo autor. A cláusula comum a todas as possíveis licenças promovidas refere-se à exigência de reconhecimento da autoria. Todas elas também permitem que cópias possam ser tiradas livremente e sem a necessidade de consulta prévia ao autor da obra que está sendo copiada. Uma outra cláusula permite ou não o uso comercial da obra liberada e uma terceira permite ou não a derivação de novos trabalhos. Caso autorizada a derivação de novos trabalhos, então o autor original pode ainda requerer ou não que a obra derivada seja liberada sob a mesma licença de uso adotada para o trabalho original.

Portanto, todas as obras liberadas sob uma licença promovida pela Creative Commons podem ser usadas livremente e sem custo, para fins não-comerciais e, dependendo das escolhas feitas pelos autores, também para fins comerciais. Se trabalhos derivados são autorizados, então a obra pode ser modificada ou uma parte dela incorporada em outra.

Suponhamos que uma foto foi liberada sob a licença menos restritiva entre aquelas promovidas pela Creative Commons, isto é, aquela que permite um uso comercial e a derivação de novos trabalhos. 
Nesse caso um recorte da foto em questão poderia ser utilizado em panfleto de propaganda de determinada empresa, contanto que os créditos devidos fossem dados ao autor da foto.

O objetivo da Creative Commons é que uma parte substancial de bens culturais seja publicada sob licenças menos restritivas para que a cultura seja novamente mais livre como ela o era durante muitos séculos e, dessa forma, promova e estimule trabalhos criativos e a inovação. Os diversos tipos de licença são gerados em três formatos: uma de forma sintética e icônica para "mortais normais", uma legível e interpretável por máquinas e uma terceira, a mais extensa, para ser lida e usada por advogados. A Faculdade de Direito da Fundação Getúlio Vargas, ${ }^{7}$ no Rio de Janeiro, é a representante da Creative Commons no Brasil. Ela traduziu as licenças "legíveis por advogados" e as adequou à legislação brasileira.

\section{Conteúdos abertos e educação}

Por que a questão de conteúdos de uso mais flexíveis é relevante para a educação? A educação é, de certo modo, incubadora da inovação e da criatividade. O sistema educacional, pelo menos em tese, deve construir e desenvolver habilidades e conhecimentos de membros da sociedade para promover tanto um crescimento individual como o desenvolvimento social. Assim, a promoção de facilidades de uso e de compartilhamento de conteúdos representa uma estratégia importante não só para a preservação da cultura, mas também para a inovação, a experimentação e o desenvolvimento.

Usualmente conteúdos necessários para alcançar determinados objetivos educacionais são adquiridos pelo Poder Público e mesmo pelos pais de alunos, ou são produzidos por professores para serem utilizados em atividades pedagógicas por eles desenvolvidas. Em um modelo de produção de "conteúdos proprietários", ${ }^{8}$ restriçōes orçamentárias e níveis baixos de renda das famílias de alunos estrangulam as opçôes da escola. Em tal modelo, os conteúdos não são igualmente acessíveis. Não é tão incomum escolas usarem textos já desatualizados em atividades de ensino. Educação não é simplesmente uma experiência "enlatada" pronta para ser consumida. Professores podem e devem usar recursos pedagógicos adequando-os a contextos específicos, atualizando-os 
para refletir avanços nas diversas áreas do conhecimento, integrando-as umas com as outras.

O desenvolvimento colaborativo de conteúdos abertos por uma comunidade envolvida especialmente com o ensino público é um modelo alternativo viável. Conteúdos gerados segundo esse modelo alternativo, por serem mais adequados a contextos específicos, têm um potencial de melhorar processos de ensino e aprendizagem (Keats, 2003).

Bens comuns, segundo Bollier (2003), consistem em "uma ampla gama de criaçôes da natureza e da sociedade que nós herdamos livremente, compartilhamos e recebemos como guardiōes para gerações futuras". A instituição escola pode, portanto, ser vista como um bem comum, sendo a educação para todos praticamente uma prioridade em todas as sociedades. Se a escola for considerada um bem comum, ela deverá ser capaz de prover as melhores experiências de aprendizagem para os seus alunos (Hepburn, 2004).

A escola, contudo, tem dificuldades em proporcionar tais experiências em razão dos acessos restritivos a recursos considerados os mais apropriados. A forma de uso de recursos proprietários por parte da escola é, em grande parte, ditada pelas condições estabelecidas, contratualmente, por corporaçóes ou indivíduos que detêm os seus direitos de propriedade, unicamente a seu critério. A escola raramente tem acesso, em quantidade e variedade, aos recursos que ela gostaria de utilizar.

As restrições de toda ordem que enfrenta ainda podem forçar a escola a fazer concessões a proprietários de recursos de seu interesse que ela não faria se pudesse ter um acesso mais fácil a tais recursos. $\mathrm{O}$ cerco de empresas do mercado cultural à escola ocorre pelo simples fato de que tais empresas vêem nos alunos da escola seus consumidores em potencial a serem cativados o quanto antes. $\mathrm{O}$ acesso aos recursos é facilitado de forma bem controlada por "licenças educacionais" com cláusulas muitas vezes questionáveis em troca de uma presença maior das empresas no espaço da escola.

Para que professores consigam obter um controle maior sobre a forma como o processo educativo é conduzido, eles mesmos e as suas instituições precisam engajar-se na produção colaborativa e no compartilhamento de recursos educacionais. É preciso formar uma comunidade de professores comprometidos com o compartilhamento e a construção de novos trabalhos derivados de trabalhos produzidos pelos demais. 
Usuários de conteúdos educacionais, portanto, precisam se tornar co-desenvolvedores e contribuir com realimentaçōes, sugestōes e melhorias. Mais do que reduzir custos, conteúdos abertos retornam o controle do processo educativo aos professores. A fim de produzir uma massa crítica de recursos próprios que tornem a iniciativa auto-sustentável, é necessário, contudo, que os professores, em número significativo, tornem-se contribuidores ativos, pois, hoje, a liberdade da "publicação digital" pertence a qualquer um que tenha acesso à Internet. Do estágio em que somente uns poucos eram capazes de escrever, a sociedade passou por diversos outros até atingir o estágio atual em que a maioria não é só capaz de escrever, mas consegue até veicular o que produz.

O processo de escrever, editar e publicar conteúdos mais substanciais, no entanto, demanda tempo, mas, se compartilhado, resultados impressionantes podem ser alcançados em prazos relativamente curtos. Imperfeiçôes podem ocorrer, em um primeiro momento, durante um processo de produção coletiva, mas são rapidamente identificadas e sanadas em um ambiente colaborativo.

\section{Promoção de uma educação mais solidária}

Como a indústria cultural opera em caráter excludente, existe uma necessidade premente de se ter acesso a diferentes meios de produção e distribuição de conteúdos, de preferência àqueles não sujeitos a pressões econômicas e políticas, e sustentados por esforços colaborativos e geograficamente distribuídos que permitam o afloramento de novas idéias e percepções. Uma nova dimensão de publicação leva o leitor a ter um novo relacionamento com o texto em virtude das expectativas, das quais ele não somente usufrua, mas que também contribua com o que é publicado.

A Internet tem o enorme potencial de ser um espaço aberto de publicação decorrente das particularidades da concepção de sua arquitetura e da sua implementação. A Internet restringe-se a passar pacotes de informação, independentemente do que eles possam representar, e deixa a "inteligência", isto é, o processamento e a interpretação dos pacotes, para as máquinas nas pontas da rede. Todo o tráfego é tratado de forma indiscriminada. Para os roteadores, que passam pacotes de um lado para o outro, tudo se constitui num fluxo sem fim de pacotes nos 
quais o que interessa para os roteadores são apenas os endereços de rede do remetente e do destinatário de cada pacote.

Tecnicamente qualquer usuário tem as mesmas chances de transmitir os seus pacotes pela Internet. Por esta razão, a despeito de todas as formas de controle social impostas pelo capital, o tráfego de informações na Internet é altamente igualitário e não discrimina ninguém que a ela tenha acesso. Além disso, todos os protocolos básicos de transmissão estão em domínio público para que os mesmos usuários possam construir aplicações baseadas em tais protocolos sem precisar pedir autorização a ninguém. Não existe uma autoridade central impondo controle sobre a Internet com relação aos fluxos de dados que nela trafegam. A combinação de uma rede que não discrimina entre os pacotes que transporta e a disponibilidade livre dos protocolos-chave viabilizou muitas das inovações mais interessantes da Internet, introduzidas, a partir da "periferia", sem a necessidade de autorização alguma.

Modelos alternativos para o desenvolvimento da educação, organizados em torno de princípios éticos de compartilhamento, tornamse, cada vez mais, uma necessidade, pois atualmente o modelo de conteúdo proprietário é, ainda, o único para muitos profissionais da área de educação. A própria natureza da educação pública clama por um compartilhamento aberto de idéias, colaboração e capacidade de construir conhecimento a partir de trabalhos entre pares.

O contexto tecnológico atual provê facilidades e componentes de software que, se devidamente combinados, são capazes de criar um ambiente colaborativo para a publicação e o compartilhamento de recursos produzidos por uma comunidade fracamente acoplada do ponto de vista social. Não é necessário que todos se conheçam bem. É preciso apenas ter interesses em comum e querer contribuir para algo maior. Por falta de mecanismos adequados para coordenar a produção de conteúdos mais substanciais por uma comunidade geograficamente dispersa, a grande maioria dos conteúdos ainda é desenvolvida de forma individual e, em geral, é de grão fino, isto é, para os quais são necessários períodos de tempo relativamente curtos para serem produzidos, como é o caso de uma lista de exercício diferentemente de um livro didático completo.

O conteúdo pedagógico pode, entretanto, ser visto como algo que se pode também criar e compartilhar. Qualquer um, mesmo aquele que se considera com menor talento criativo, pode participar e con- 
tribuir com algo em um processo de produção coletiva. Um professor, em particular, gera, ao longo de sua carreira, um conjunto muito rico de conteúdos produzidos por ele próprio, mas que é subutilizado por falta de mecanismos eficientes de publicação e compartilhamento de contribuições essencialmente de granularidade mais fina.

A preparação de aulas requer, muitas vezes, uma coleta de materiais de diferentes fontes. O professor seleciona, então, fragmentos dos diversos materiais coletados e integra-os com contribuiçōes próprias. Alguns dos fragmentos precisam, eventualmente, ser retrabalhados para que sejam adequados ao contexto específico de aprendizagem. O novo conteúdo não está necessariamente bem acabado, já que o professor, muitas vezes, contenta-se apenas com um esboço de seu plano de aula. Com um pequeno esforço adicional, tal esboço pode transformar-se em algo aproveitável também por outros professores. As condições necessárias para o reaproveitamento de um recurso gerado por um professor são: motivação para o professor investir um pouco mais no acabamento de sua produção, condições de uso mais flexíveis que permitam um reuso e uma adequação de conteúdos e, finalmente, facilidades de publicação e difusão.

Tornar um conteúdo disponível na Internet, contudo, não garante, segundo Vuorikari (2004), a sua localização e o reuso por alguém que dele necessite. Outro problema é o de certificação de sua qualidade. Muitas vezes não fica claro se a origem da informação veiculada é fidedigna e se a informação prestada é precisa. Cabe ao usuário a decisão final sobre isso sem que ele disponha, na maioria das vezes, de elementos para tal julgamento.

A publicação em um repositório temático alivia, em parte, o problema, pois restringe o universo de busca. Para uma recuperação de maior precisão é interessante agregar metainformaçōes, isto é, informações sobre os conteúdos publicados. $\mathrm{O}$ uso de metainformaçōes melhora significativamente a qualidade de retorno de serviços de busca para as consultas feitas pelos usuários.

A questão da qualidade de um conteúdo poder ser resolvida, de forma satisfatória, se forem criados mecanismos que permitam registrar e veicular avaliações de tal conteúdo por terceiros. Novos usuários conseguem, então, beneficiar-se de avaliações prévias.

Áreas de conhecimento não são isoladas umas das outras. Uma outra leitura pode ser introduzida se associações entre conteúdos são 
explicitadas e anotadas para comentar a razão do estabelecimento de cada associação. Associações, portanto, contextualizam melhor os conteúdos e facilitam o seu entendimento por parte dos usuários.

Além de prover guias, modelos e melhores práticas, um ambiente colaborativo para a produção de conteúdos abertos deve apoiar a difusão de conhecimentos, por meio de facilidades de publicação mais acessíveis a um público mais amplo, e incentivar o compartilhamento para promover produções inovadoras desenvolvidas com menos "fricção", isto é, para proporcionar condiçôes menos limitantes e inibidoras para o reuso criativo de conhecimentos prévios com relação às impostas usualmente. Tais facilidades de produção de conteúdos abertos acabam estimulando e fortalecendo comunidades organizadas em torno de interesses comuns e objetivos maiores. Um ambiente colaborativo precisa ser construído a partir de: modelos de colaboração que se baseiem claramente em papéis e responsabilidades, um modelo de ciclos de vida bem definido para conteúdos e processos de trabalho que cubram as diversas atividades no âmbito de cada ciclo.

\section{Ambiente Yai}

Com o intuito de oferecer ao professorado de escolas públicas a oportunidade de publicar e compartilhar conteúdos abertos, foi desenvolvido um ambiente colaborativo de nome Yai. ${ }^{9} \mathrm{O}$ codinome "Yai" significa onda, no dialeto mbyá do guarani (Dooley, 1998). Como ondas que se propagam ao se jogar uma pedra em um lago, um conteúdo de interesse educacional pode ter seu impacto potencializado se for compartilhado e as suas formas de reuso flexibilizadas. O ambiente Yai objetiva ser o catalisador dessa potencialização.

O sistema Yai foi produzido como software de código aberto ${ }^{10} \mathrm{e}$ consiste em um diretório eletrônico organizado hierarquicamente em temas e subtemas. O colaborador, no papel de "autor doador", ao submeter um conteúdo a ser compartilhado, escolhe uma possível variante de licença de uso, entre as promovidas pela Creative Commons, sob a qual gostaria de publicar a sua contribuição. Além disso, também fornece um breve comentário sobre a sua contribuição e sugere o local na hierarquia do diretório eletrônico que considera o melhor para a sua publicação. 
O conteúdo submetido não é tornado público de imediato. Um outro usuário de sistema, no papel de "catalogador", após selecionar a contribuição de um repositório reservado de conteúdos sob análise, verifica se a contribuição está alinhada com os objetivos da iniciativa. Se não o for, ela é eliminada e o seu autor doador é notificado sobre os motivos do descarte. Em caso afirmativo, o catalogador verifica a qualidade da contribuição e dos comentários complementares enviados pelo autor doador bem como a adequação da sugestão do local de publicação no diretório eletrônico. Enquanto o catalogador considerar necessárias as melhorias, ele as negocia com o autor doador, via o próprio sistema. Depois de chegar a um acordo, a contribuição é tornada pública para todos os usuários do sistema no papel de "visitantes" à procura de conteúdos que satisfaçam as suas demandas.

Existe um outro tipo de usuário, cujo papel é denominado "comentarista". Um comentarista constrói coletâneas de associações anotadas estabelecidas entre conteúdos mantidos no diretório eletrônico. Cada coletânea aborda uma questão particular de forma interdisciplinar. Uma coletânea quebra a estrutura hierárquica imposta pela organização do diretório eletrônico ao estabelecer uma teia de conteúdos identificados como relacionados pelo comentarista. As anotações de associaçôes são textos livres que podem registrar, entre outras informações, as justificativas pelo estabelecimento das associaçóes e as dependências entre os conteúdos. O objetivo é contextualizar melhor os conteúdos ao mostrar explicitamente alguns dos seus inter-relacionamentos.

Ao visitante, portanto, são facultadas primordialmente duas formas de navegação: uma pela hierarquia do diretório eletrônico para verificar quais conteúdos se encontram agrupados sob um particular tema, e outra por meio de percursos ao longo de associações pertencentes a uma mesma coletânea. Além disso, o sistema provê também um mecanismo de busca pelo qual o visitante pode procurar por palavras-chave.

Os usuários catalogadores e comentaristas são voluntários que se cadastraram no sistema para exercer tais papéis. Qualquer um motivado para tais atividades pode se cadastrar e pode exercer aqueles papéis enquanto o seu trabalho for considerado satisfatório pelos seus pares.

O sistema Yai não dá suporte a autores doadores diretamente na produção dos seus conteúdos, mas os apóia na publicação. Os trabalhos submetidos são, em geral, de grão fino (isto é, requerem apenas 
um período de tempo relativamente curto para serem produzidos) e desenvolvidos de forma individual. As atividades de catalogadores e comentaristas são desenvolvidas de forma "anárquica". Dentro da área de suas competências estabelecidas pelos papéis que desempenham, tais usuários podem revisar e alterar os trabalhos realizados por seus pares ou até mesmo removê-los do sistema se julgados inadequados.

Qualquer um dos usuários pode se declarar interessado em determinado artefato (conteúdo, coletânea, associação e comentário) mantido pelo sistema. Se um artefato é alterado ou modificado, todos os interessados nele são notificados para que possam verificar se alguma ação corretiva se faz necessária, em razão das mudanças ocorridas.

Coletâneas e anotaçōes são, portanto, produzidas por uma comunidade sem que seja a elas atribuída uma autoria particular diferentemente do que ocorre com os conteúdos. Um conteúdo tem um ou mais autores claramente identificados e cabe a eles a responsabilidade pela evolução de suas produções. Toda nova versão precisa ser outra vez negociada com um catalogador.

Ao passo que um conteúdo representa o conhecimento de um indivíduo ou de um pequeno grupo, o conjunto das coletâneas no sistema Yai representa um conhecimento construído e depurado coletivamente, tendo como elementos básicos conteúdos do diretório eletrônico integrados para formar algo maior por meio de associações explícitas. Ao serem integrados para formar coletâneas, tais conteúdos têm maior valor agregado.

\section{Comentários finais}

A publicação, aconteça ela em qualquer meio, é um dos canais mais importantes de disseminação de conhecimento. Maiores facilidades de publicação e a flexibilização de uso melhoram ainda mais os processos de criação e o reuso de conhecimentos. Estes, por sua vez, estimulam o desenvolvimento econômico e social. A geração de conteúdos abertos representa, portanto, uma estratégia potencial e interessante, particularmente para países em desenvolvimento.

A Internet é um meio de colaboração por excelência, por ser ela igualitária e não discriminatória nas trocas de informações e não ter um controle centralizado a despeito das limitaçôes que obrigatoriamente 
são impostas pelo capital. Em processos colaborativos de conteúdos abertos, sustentados pela Internet, participantes normalmente não esperam receber uma remuneração financeira em troca. As motivações são sutis e variadas tais como o crescimento de reputação, a oportunidade de trabalhar em uma comunidade de pessoas com valores e objetivos semelhantes e a liberdade de criar sem a supervisão de um chefe. Oportunidades abundantes costumam ser oferecidas para facilitar a participação de todos os interessados, os quais, em algumas iniciativas, passam da casa dos milhões.

Para proteger a comunidade de colaboradores de apropriações indevidas do esforço conjunto, licenças de uso são apresentadas como instrumentos legais que, normalmente, objetivam garantir o reconhecimento da autoria e promover a distribuição livre e aberta do conhecimento construído coletivamente.

Em particular para a escola, que pode ser considerada um bem cultural comum, a disponibilidade de um grande volume de conteúdos abertos de interesse educacional seria de grande valia. Um volume da magnitude desejada só pode ser obtido e mantido com o envolvimento da comunidade escolar. A motivação principal para tal envolvimento é a possibilidade de um maior controle sobre a condução dos processos de ensino e aprendizagem, hoje limitado por proprietários de conhecimentos de particular interesse para a escola.

O sistema Yai é um veículo tecnológico para publicar e difundir conteúdos abertos e de registro de conhecimento construído coletivamente na Internet. O elemento mais importante da iniciativa não é, contudo, a ferramenta, mas a comunidade de usuários da ferramenta. Sem o envolvimento dos profissionais da área de educação, a ferramenta não terá cumprido seus objetivos.

Recebido em dezembro de 2005 e aprovado em janeiro de 2006.

Notas

1. O termo "conteúdo" é utilizado, no presente texto, para designar qualquer recurso em formato digital.

2. Em 1998, os Estados Unidos adotaram o Digital Millenium Copyright Act, um texto normativo que modifica profundamente o regime de proteção à propriedade intelectual. Tal norma, entre outros aspectos, criminalizou qualquer iniciativa que possa vir a violar me-

Educ. Soc., Campinas, vol. 27, n. 94, p. 257-276, jan./abr. 2006

Disponível em <http://www.cedes.unicamp.br> 
Conteúdos abertos e compartilhados: novas perspectivas para a educação

canismos técnicos à proteção de direitos à propriedade intelectual e estende a terceiros a responsabilidade pela violação de direitos autorais. Provedores de acesso e de serviços na Internet são considerados co-responsáveis caso os seus usuários infrinjam direitos autorais por meio dos serviços por eles prestados. Uma conseqüência foi a retirada maciça de conteúdos da Internet, nos Estados Unidos, que pudessem dar qualquer brecha a processos judiciais. Em discussões sobre a ALCA e na Organização Mundial do Comércio, fortes pressóes são exercidas para a adoção, em escala global, de normas equivalentes ao Digital Millenium Copyright Act.

3. A partir dos fins da primeira metade do século, com o término da Segunda Guerra Mundial, de certa forma ainda estupefata pela absorção de suas horríveis seqüelas, a sociedade, mobilizada pela propaganda e pelo consumo, pela tecnociência aplicada à informação, pela intensa difusão da comunicação visual, passou a assumir novas feições. Abriu-se, então, espaço para a crítica de um ideal de racionalidade institucionalizado. Essa crítica permite pensar, em toda a sua complexidade, mecanismos sociais concretos em razão dos quais se dá a gestão das consciências. Estão aí situados os trabalhos da Escola de Frankfurt em cujo contexto encontramos o célebre conceito de "indústria cultural" cunhado por Adorno e Horkheimer, em 1947. Para eles não se trata apenas de constatar a existência do capital atuando "na indústria do entretenimento", mas do exercício de controle do período de lazer - o controle do tempo livre - em que "produtos culturais" são postos à disposição dos "consumidores" para mantê-los alertas e treinados. A arte, neste sentido, não só se torna integralmente mercadoria, mas também eficiente mecanismo de controle social.

4. Conteúdo aberto ou conteúdo livre (open content em inglês), termo cunhado por analogia com código-fonte aberto (open source), descreve qualquer tipo de trabalho criativo (por exemplo, artigos, imagens, áudio, vídeo etc.) que pode ser utilizado sem (ou com apenas algumas) restriçóes legais (apresentando-se como de domínio público ou publicado sob uma licença de direitos de autor não-restritiva), sendo distribuído em formato que, explicitamente, permite a cópia da informação. A expressão "conteúdo aberto" descreve também aquele conteúdo que pode ser modificado por qualquer um. Demandam, entretanto, revisão por outras partes atuantes - mas não há um grupo fechado como editores comerciais responsáveis por todas as alterações (adaptação do verbete encontrado na Wikipédia, em http://pt.wikipedia.org/wiki/Conteúdo_aberto).

5. Disponível em: <http://www.filmsite.org/stea.html>.

6. Disponível em: <http://creativecommons.org/>.

7. Disponível em: <http://www.direitorio.fgv.br/cts/>.

8. Terminologia empregada na área de software para indicar propriedade privada.

9. Uma versão operacional do sistema Yai encontra-se em http://yainet.org/. O sistema foi concebido no âmbito de um trabalho de mestrado desenvolvido no Instituto de Computação da Unicamp por Osmar Mantovani, sob a orientação de Hans Liesenberg e assessoria de Maria Helena Pereira-Dias. Em 2004, o projeto encontrou-se entre os selecionados pelo Programa de Apoio à Pesquisa em Educação a Distância (PAPED) da CAPES.

10. Em http://iv.incubadora.fapesp.br/yai/portal encontram-se disponíveis todos os detalhes técnicos do sistema Yai e o respectivo pacote tecnológico publicado como software de código aberto, isto é, o seu código-fonte, aquele legível por pessoas, é público. 
Referências bibliográficas

BARTHES, R. et al. Lingüistica e literatura. Trad. de Isabel Gonçalves e Margarida Barahone. Lisboa: Edições 70, 1968.

BARTHES, R. O prazer do texto. Trad. de J. Guinsburg. São Paulo: Perspectiva, 1987.

BOLLIER, D. Preserving the commons in the new information order. 2003. Disponível em: <http://world-information.org/wio/readme/ 992007035/1078492038>. Acesso em: 16 abr. 2005.

CEDERGREN, M. Open content and value creation. First Monday, v. 8, n. 8, ago. 2003. Disponível em: <http://firstmonday.org/issues/ issue8_8/cedergren/>. Acesso em: 16 dez. 2005.

DOOLEY, R.A. Léxico guarani, dialeto mbyá. Curitiba: Sociedade Internacional de Lingüística, 1998. Disponível em: <http://www.sil.org/ americas/brasil/PUBLCNS/DICTGRAM/GNDIC.pdf>. Acesso em: 16 dez. 2005.

FONTES, J.B. Eros, tecelão de mitos: a poesia de Safos de Lesbos. São Paulo: Estação Liberdade, 1991.

FOUCAULT, M. O que é um autor? Trad. de Antônio Fernando Cascais e Edmundo Madeira. Lisboa: Vega/Passagens, 1992.

GENETTE, G. Palimpsestes: la littérature au second degré. Paris: Seuil, 1981. (Collection Points Essais, n. 57)

HEPBURN, G. Seeking an educational commons: the promise of open source development models. First Monday, v. 9, n. 8, ago. 2004. Disponível em: <http://firstmonday.org/issues/issue9_8/hepburn/>. Acesso em: $16 \mathrm{dez} .2005$.

HIETANEN, H. Open content licesing: case creative commons. 2003. Disponível em: <http://www.hiit.fi/de/creativecommons/ OpenContenCase_CC.pdf>. Acesso em: 16 dez. 2005.

KEATS, D. Collaborative development of open content: a process model to unlock the potential for African universities. First Monday, v. 8, n. 2, fev. 2003. Disponível em: <http://firstmonday.org/issues/ issue8_2/keats/>. Acesso em: 16 dez. 2005.

Educ. Soc., Campinas, vol. 27, n. 94, p. 257-276, jan./abr. 2006 
Conteúdos abertos e compartilhados: novas perspectivas para a educação

KIENLE, H.M. et al. Intellectual property aspects of web publishing. In: SIGDOC'04, ACM, out. 2004. Anais... p. 136-144.

LANDOW, G.P. Hipertexto: la convergencia de la teoría crítica contemporánea y la tecnología. Trad. de Patrick Ducher. Barcelona: Paidós, 1995.

LEMOS, R. Direito, tecnologia e cultura. Rio de Janeiro: FGV, 2005.

LESSIG, L. Free culture: how big media uses technology and the law to lock down culture and control creativity. Nova York: Penguin, 2004.

PEREIRA-DIAS, M.H. Encruzilhadas de um labirinto eletrônico: uma experiência hipertextual. 2000. Disponível em: <http://www.unicamp.br/ -hans/mh/principal.html>. Acesso em: 16 dez. 2005.

VUORIKARI, R. Methods for sharing open source content: the school network's perspective. 2004. Disponível em: <http://www.eun.org/ insight-pdf/open_content_vuorikari.pdf >. Acesso em: 16 dez. 2005. 